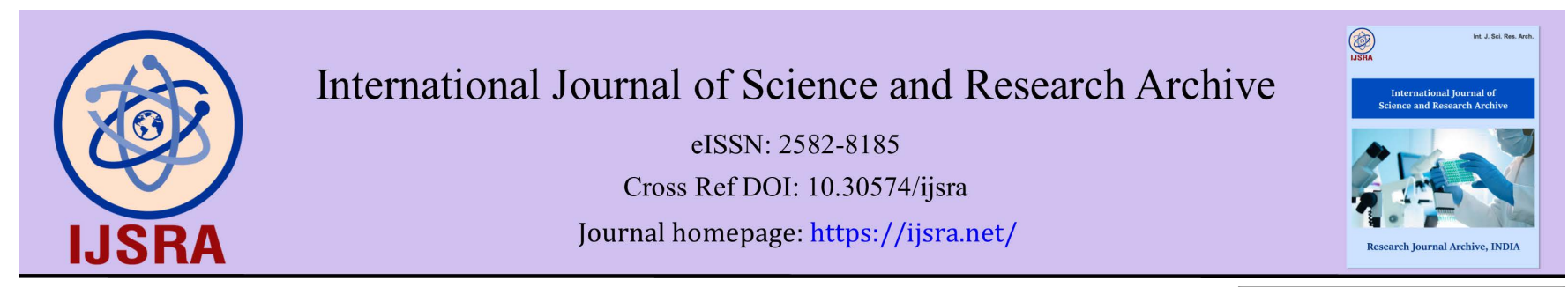

(REVIEW ARTiCLE)

\title{
Canine parvovirus: A review
}

Rawaa Saladdin Jumaa *, Dhuha Ismael Abdulmjeed, Sabrin Ibraheem Mohsin and Osama F Atshan

Department of Microbiology of Veterinary Medicine, College of Veterinary Medicine, University of Baghdad, Iraq.

International Journal of Science and Research Archive, 2021, 03(02), 193-200

Publication history: Received on 18 September 2021; revised on 19 October 2021; accepted on 21 October 2021

Article DOI: https://doi.org/10.30574/ijsra.2021.3.2.0140

\begin{abstract}
Canine parvovirus (CPV) is a non-enveloped and single-stranded DNA virus. This virus is belonging to parvoviridae family that necessitates quickly dividing cells to replicate. On the other hand, it is extremely hardy, withstanding many common disinfectants and staying alive for months to years in ground surface or on fomites. This virion is an icosahedral symmetry. It has rough surface and form a triangular units. The parvoviruses have two sizes of viral proteins: small (VP2-5) and large (VP1).
\end{abstract}

This virus is classified into three strains that widely recognized: CPV2a, CPV2b and CPV2c. It is extremely contagious and therefore is distributed from canine to canine via fecal oral contact. It has been reported worldwide. Sources of stress includes early weaning, overcrowding, and parasite load. On the other hand, lacking of the active or passive immunity, geographic area, and the incidence of other pathogens are all related to the development of clinical parvovirus disease. Puppies have been identified to have a more severe case of the disease than older dogs.

There are two clinical forms: gastro-enteritis and myocarditis. The gastroenteritis form is general in dogs, while the myocarditis form is public in puppies. The symptoms of the disease include fever, leucopenia, anorexia, vomiting, diarrhea, dehydration. This disease was primarily controlled through hygienic measures and vaccination. The interference of maternal antibodies is thought to be a main reason of CPV immunization failures in puppies.

The viral diagnosis is confirmed using different laboratory methods such as direct and indirect examination. The direct methods include viral isolation, detection of viral morphology, detection of viral antigen and detection of viral genome. As well as the indirect methods include detection the specific antibodies against virus.

Keywords: Canine parvovirus; Dogs; Puppies; Bloody diarrhea

\section{Introduction}

Canine parvovirus (CPV) is a vertebrate-infecting virus in the family Parvoviridae (Tijssen et al., 2017; De et al., 2018; Cotmore et al., 2019). The CPV is $98 \%$ which similar to feline panleukopenia virus. As well as, it is only differing in 6-7 amino acids of the VP2 capsid protein (Ogbu et al., 2020).

It is also associated to the mink enteritis virus, the raccon parvovirus and the blue fox parvovirus. Canine parvovirus type 2 had been designated to differentiate it from parvovirus of dogs known as canine minute virus. The actual canine parvovirus evolved into CPV1 and CPV2. The CPV2 is antigenetically analogous to CPV1 (González et al., 2020).

\footnotetext{
* Corresponding author: Rawaa Saladdin Jumaa

Department of Microbiology of Veterinary Medicine, College of Veterinary Medicine, University of Baghdad, Iraq. 
Several authors believe the CPV2 morphed as of feline parvovirus (De et al., 2018; Ogbu et al., 2020). CPV2a was discovered at 1978. It differed from CPV2b with seven amino acid replacements and one epitope. CPV2b first popped up in 1984 and quickly became the most common CPV variant worldwide by 1988 (Horwitz 2018; Decaro et al., 2020).

The most recent variant, CPV2c, was discovered in Italy in 2000, and then spread to other countries (Ogbu et al., 2017). In some codon, the CPV2c differentiates from canine parvovirus types $2 \mathrm{a}$ and $2 \mathrm{~b}$ (Ogbu et al., 2020). As a result, there is little antigenic modification between CPV2a, CPV2b, and CPV2c when compared to the variation between CPV2 and the three variants (Ogbu et al., 2017; Decaro et al., 2020).

Because of the etiology's complexity, viral diarrhea is common in canine disease, causing serious harm to the canine industry and dogs. Numerous viral pathogens, including canine parvovirus (CPV), canine distemper virus and canine coronavirus (CCoV) are currently linked to canine diarrhea (Mazzaferro, 2020).

CPV is leading to cause the morbidity and mortality in dogs, particularly puppies, in an around the world (Kennedy, 2020). Variation, recombination, and co-infection have been shown to intensify clinical symptoms and pose a challenge to CPV infection prevention and control (Castillo et al., 2020). Dogs infected with CPV develop illness within 3-7 days that displaying severe gastroenteritis, lethargy, vomiting and diarrhea (usually bloody) (Terzungwe et al., 2018).

In this review, the characteristics of canine parvovirus were summarized, including viral classification, viral structure, and viral genome. Also, it aimed to study about CPV epidemiology, pathogenesis and how to control this disease.

\section{History}

Due to their small size, parvoviruses were moderately revealed late in evaluation to other prominent viral families. In the late of 1950 (Schatzberg et al., 2002) and early of 1960 (ICTV 2006) a number of animal parvoviruses had been observed that containing the mouse minute virus (Horiuchi et al., 1998; Shackelton et al., 2005; Truyen, 2006). Yvonne Cossart and his colleagues were discovered the first pathogenic human parvovirus in 1974. After that, the virus was discovered using electron microscope as animal parvovirus and classified as B19 by the International Committee on Taxonomy of Viruses (ICTV) in 1985. Then, it became increasingly related with various diseases during the 1980s (Ikeda et al., 2000).

Parvoviruses (PVs) were categorized in the genus Parvovirus by classification of the ICTV's which was first report in 1971 (Shackelton et al., 2005, Truyen, 2006). PVs were indorsed to the rank of family in 1975 and stayed undefined to until 2019 (Ikeda et al., 2000).

In 2019, this family has been discovered, rejecting the traditional invertebrate vertebrate difference between Parvovirinae and Densovirinae. This differentiating of the subfamilies is relying on helicase phylogeny (Truyen, 2006). PV get its name from Latin words parvum (parvus) which mean small size or tiny of parvovirus virions to comprise other viruses (Oh et al., 2006).

\section{Viral classification}

Canine parvovirus was classified as group II (ssDNA) in accordance with Baltimore Classification. Also, it was classified in accordance with the international committee taxonomy on viruses (ICTV) as shown in Table 1.

Table 1 Explain taxonomy of Canine Parvovirus (CPV) (ICTV, 2006; Cotmore et al., 2019)

\begin{tabular}{|l|l|}
\hline Group & Group II (ssDNA)(Baltimore classification) \\
\hline Order & Piccovirales \\
\hline Family & Parvoviridae \\
\hline Genus & Protoparvovirus \\
\hline Species & Carnivore protoparvovirus 1 \\
\hline Virus & Canine parvovirus \\
\hline
\end{tabular}




\section{Virology of canine parvoviruses}

There are two distinct canine parvoviruses. Canine Minute virus or Canine Parvovirus type 1 and Canine Parvovirus Enteritis or Canine Parvovirus type 2

\subsection{Canine parvovirus type 1}

Canine Adeno associated virus, also known as Canine Parvovirus Type 1 or Canine Minute Virus, is a non-pathogenic virus. The parvovirus was isolated from the fecal samples of a healthy dog. Although it is common, it is not as pathogenic as CPV-2. Also, it is antigenically different from CPV-2 but it is similar to Bovine parvovirus genetically. CPV-1 caused mild diarrhea, pneumonia, myocarditis and lymphadenitis in puppies of (5-21) days old. The majority of affected puppies have a mild disease, but some may have a more serious clinical form known when fading puppy syndrome. Because of its similarity to CPV2, CPV-1 causes infertility in bitch, stillbirth or abortion in pregnant bitch, and the use of PCR or immunoelectron microscopy is required to diagnose CPV-1 (Terzungwe et al., 2018; Dong et al., 2020).

\subsection{Canine parvovirus type 2}

is a highly pathogenic virus that affects both domestic and wild canids. Also, this virus is a single-stranded, non-envelop and has DNA genome. It is also particularly resistant to a variety of disinfectants, but it is susceptible and destroyed by sodium hypochloride. Furthermore, it is highly mutagenic. It differs from Feline Panleucopenia virus and Mink Enteritis Virus by only a few DNA bases in its of viral capsid, therefore it may be still in the evolving stage and evolved from mutations from Feline Panleucopenia virus or other carnivore Parvoviruses (Ogbu et al., 2017; Terzungwe et al., 2018; Dong et al., 2020).

\section{Viral structure}

Parvovirus virion is an icosahedral symmetry and 23-28 nanometers in a diameter. It has rough surface because of the capsid is made up of sixty of polypeptide chains to form a triangular units (Holmes et al., 2013; Hartmann, Steutzer, 2014). For different parvoviruses, the viral protein (VP) is expressed in two sizes: small (VP2-5) and large (VP1).

The VP1 is extended to significant regions of replication cycle. While the smallest VP2-5 share a public C-terminus but have different N-terminus in lengths. Also, it is responsible for assembly step of virus (Ettinger, Feldman, 1995, Hartmann, Steutzer, 2014).

Each monomer of VP has a structure of core beta-barrel identified as the roll motif. Each of motif consists eight strands settled in two adjacent of antiparallel $\beta$ sheets characterized as BIDG and CHEF. These beta strands are linked together by loops of varying length, sequence and conformation (Ettinger, Feldman, 1995; Hartmann, Steutzer, 2014).

\section{Viral genome}

The PVs have a ss-DNA which have the transcriptional activation domain. This domain promotes the transcription acitivity and overlapping the open reading frames. On the other hand, this domain was encoded the supportive proteins that involved in numerous features of the viral replication. The gene of VP encodes the viral protein (VP) that responsible for the formation of the viral capsid (Hartmann, Steutzer, 2014).

The coding region of viral genome is folded and flanked into structure knowen as hairpin loop. These loops have the information of cis acting that essential for DNA packaging and replication. Also, these hairpin loops act as hinges for modification the replication way (Silverstein, 2003; Macintire, 2008; Hartmann, Steutzer, 2014).

\section{Replication or life cycle of CPV}

The replication of CPV is nuclear replication. The steps of replication include: attachment of the virus to the host cell via a variety of cellular receptors to initiates clathrin-mediated endocytosis. After that, the penetration of the virus into the cytoplasm via permeabilization of host endosomal membrane then, the virus lead to change conformation in endosomes via the phospholipase A2 (PLA2) of viral VP1, which allowing the virion to penetrate lipid bilayer membranes for un coating the virus from capsid (Hartmann, Steutzer, 2014).

After that, microtubular transport or intracellular trafficking of the virion toward the nucleus for starting the replication of viral genome or viral genome (ssDNA) penetrate the nucleus. Afterwards, the viral DNA remain in nucleus until host 
cell enters S phase. When the nucleus of infected cells enters the S phase, the viral DNA start transcription to produce the viral mRNA and then translated to viral proteins (Savigny, MacIntire, 2010).

This replication occurs through rolling-hairpin mechanism via viral non-structural protein (NS1endonuclease) and produces the viral genome (Martin et al., 2002; Kuwabara et al., 2006; Hartmann, Steutzer, 2014; Marks 2016). Subsequently, the capsid protein accumulated in nucleus and assembled as empty capsid (Ogbu et al., 2017). Following that, the releasing of complete virion is exported from nucleus into the external of the host cells. Some studies indicated the releasing of the virus due to cellular lysis through cellular necrosis or apoptosis. (Hartmann, Steutzer, 2014; Ogbu et al., 2017).

\section{Epidemiology}

The infectious disease of puppies was discovered at 1970 and recognized the virus as causative agent of haemorrhagic gastroenteritis in dogs (Appel et al., 1979; Dogonyaro, 2010). This disease was also described in Canada, Australia, the United Kingdom, New Zealand, and Belgium. In 1980, the virus detected via using of specific monoclonal antibodies (Hong et al., 2007).

In 1985, the CPV2b revealed in Nigeria, United States, South Africa, and Turkey (Dogonyaro, 2010; Ogbu et al., 2017). Also, all ages, breeds and sexes have been infected with CPV2 (Gombac et al., 2008). Furthermore, the incidence of infection occurs between 6 weeks and 6 months (Steinel et al., 2000; Tilley, Smith, 2011; Chollom et al., 2013).

The disease is more contagious and transmitted via the fecal oral route (Khan, Line, 2005). The incubation period of CPV is 4-5 days in the field, but in experimental infection the incubation period of CPV is 3 days. Also, the virus is resistant to several disinfectants such as detergent and is stable to heat and alcohol (Ernest, 2009).

\section{Clinical signs}

Clinical signs of diseased dogs range from asymptomatic disease to fulminant disease with sudden death which seen in young and immunocompromised breeds. Canine parvovirus infection occurs clinically in two ways: myocarditis and gastroenteritis. Early infection in puppies causes myocardial necrosis through either acute cardio pulmonary failure or heart failure (Khan, Line, 2005; Dogonyaro, 2010; Ogbu et al., 2017).

Canine parvovirus gastroenteritis is also most popular in puppies aged 6 to 20 weeks, when maternal antibody defense is waning and vaccination has still not fully protected the puppies against infection (Mosallanejad et al., 2008; Dogonyaro, 2010; Ogbu et al., 2017). The feverish or hypothermia, depression, anorexia, vomiting, dehydration, and foul-smelling bloody diarrhea in addition, to clinical signs, the haematological findings include thrombocytopenia and leucopenia. Also occurrence of hypovolemic shock was due to large fluid and protein losses (Ettiger, Feldman, 2005; Ogbu et al., 2017).

\section{Pathogenesis}

Following ingestion, the virus replicates in the lymphoid tissues of the oropharynx, from which it spreads to the bloodstream, where it attacks rapidly dividing cells throughout the body, particularly those in the bone marrow, lymphopoietic tissues, and crypt epithelia of the jejunum and ileum (Khan, Line, 2005) and (in young dogs) myocardial cells (Ettiger, Feldman, 2005).

The lymphatic infection occurs before intestinal infection due to replication of the virus in and lymphopoetic tissue of the bone marrow. This lymphatic infection induced the haematological findings such as lymphopenia and neutropenia. After 3 days of lymphatic infection, the crypt cells of intestine are splitting. This intestinal infection induces the clinical symptoms such as hemorrhagic diarrhea caused primarily by elevated intestinal permeability (Khan, Line, 2005; Ettiger, Feldman, 2005). Ordinary enteric bacteria, such as Escherichia coli and Clostridium perfringens invade the mucosa and bloodstream, causing bacteremia (Khan, Line, 2005). 


\section{Diagnosis}

The critical to diagnose canine parvovirus infection which based on clinical signs. In addition to laboratory tests should always be used to confirm a clinical diagnosis of canine parvovirus infections (Dogonyaro, 2010). Several laboratory methods for detecting canine parvovirus in infected dogs' feces have been developed. They consist of direct and indirect examination. The direct examination of CPV include viral isolation (VI), electron microscopy (EM) (Alicia et al., 1999), ELISA test, immune chromatographic tests (IC), haemagglutination test, inhibition of haemagglutination test, polymerase chain reaction (real time and conventional PCR) (Desario et al., 2005).

- Viral isolation methods: The isolation of CPV on living cells such as cell culture for produce the cytopathic effect and to detected the viral antigen via haemagglutination test or immunofluorescence (IF) assay (Desario et al., 2005).

- Electron Microscopy: Electron microscopy, as a diagnostic tool, allows for the visualization of minute objects as tiny as one nanometer (Alicia et al., 1999; Khan, Line, 2005).

- Immunochromatography Test (ICT): Because the test procedure is simple, the immunochromatography test is a field and rapid diagnostic method which used in the clinical practice. As a result, both veterinarians and owners can perform it. This test is capable of detecting three viral variants (CPV2a, CPV2b, and CPV2c) (Ettiger, Feldman, 2005; Desario et al., 2005; Dogonyaro, 2010; Ogbu et al., 2017).

- Enzyme-Linked Immunosorbent Assay (ELISA): The ELISA technology, an easy to use in clinic procedure called rapid test has been developed for detection the titer of IgG antibody in the serum of vaccinated dogs and puppies (Ettiger, Feldman, 2005; Ogbu et al., 2017).

- Lateral Flow Immunoassay Test (LFAT): is a simple diagnostic test that can be achieved under most conditions and is an easy and quick mainly used in the field (Dogonyaro, 2010).

- Haemagglutination test (HA): This method is used for quantifying viruses through HA. It is a rapid, simple and easy method that can be used for large number of specimens. These viruses have haemagglutinins on their surfaces that can agglutinate red blood cells via bridge formation with receptors of red blood cells (Desario et al., 2005; Dogonyaro, 2010).

- Haemogglutination Inhibition Test (HI): is most commonly used for evaluation the titer of maternally antibodies. Furthermore, the HI test is used for determination the amount of antibody that specific to viral antigen (Desario et al., 2005). This test has two types: rapid detection of virus known alpha method and evaluate the titer of antibodies in serum samples known as beta method (Dogonyaro, 2010).

- Molecular Detection: The diagnosis of CPV infection via molecular detection is based on the detection of viral DNA. this test is highly sensitive and most accurate for CPV diagnosis (Desario et al., 2005; Dogonyaro, 2010). The molecular detection include: conventional and real time PCR. But this test required expensive equipment, reagents and skilled personnel (Desario et al., 2005).

\section{Treatment}

The treatment should be including intravenous fluids, vomiting suppression, and antimicrobial drugs. The solution therapy is the administration to restore and maintain hydration and to maintain normal serum potassium and glucose concentrations. Also the controlling of vomiting with antiemetic drugs (Macintire, 2004; Dogonyaro, 2010; Ogbu et al., 2017).

\subsection{Prevention and control}

Because the disease is extremely contagious and virulent, the prevention is only system to keep puppy or dog healthy. The virus is very stable, and it is survive for over a year in fecal samples and other materials for example soil (Dogonyaro, 2010).

It can withstand extreme cold and heat. Chlorine-based household disinfectants are the only ones that kill the virus. The chlorine bleach is used to disinfect the contaminated items and infected area (Macintire, 2004; Ernest, 2009).

The viral shedding remains for few days after recovers from CPV in feces (Dogonyaro, 2010). These feces are primary sources in environment for viral risk. The vaccination is important against CPV. Therefore, the booster vaccination is very important for puppies because it produce effective levels of immunity (Ernest, 2009). 


\section{Conclusion}

We concluded from our review that canine parvovirus remained a highly contagious, severe, infectious illness with a wide geographic distribution. Several tests were also used to diagnose the infection. In addition, the virus was divided into three stains, all of which generated two different clinical manifestations: gastroenteritis and myocarditis. In the future, research should concentrate on deciphering the mechanism of cell death as well as the mechanism of disease prevention vaccines.

\section{Compliance with ethical standards}

\section{Acknowledgments}

The authors thanks Aida B. Allawe for her support us during the writing of this review.

\section{Disclosure of conflict of interest}

All authors declare that they have no conflict of interest.

\section{References}

[1] Alicia N, Adriana N, Miguel A. Detection of viral particles in faeces of young dogs and their relationship with clinical signs. Review of Microbiology. 1999; 30: 237-241.

[2] Appel M, Scott F, Carmichael L. Isolation and immunization studies of a canine parvo like from dogs with haemorrhagic enteritis. Veterinary Record. 1979; 105: 156-159.

[3] Castillo C, Neira V, Aniñir P, Grecco S, Pérez R, Panzera Y, Ortega R. First molecular identification of canine parvovirus type 2 in Chile reveals high occurrence of CPV2c antigenic variant. Frontiers in Veterinary Science. 2020; 7: 194.

[4] Chollom S, Fyaktu E, Okwori A, Agada G, Hashimu G, Akele R, Voumangai E, Dash T, Egah D. Molecular detection of canine parvovirus in Jos, Nigeria. J. Vet. Medicine Animal Health. 2013; 5(2): 57-59.

[5] Cotmore S, Agbandje MM, Canuti M, Chiorini JA, Eis HA, Hughes J, Consortium I. ICTV virus taxonomy profile: Parvoviridae. Journal of General Virology. 2019; 100(3): 367.

[6] De L, Mafla E, Puga B, Erazo L, Astolfi F, Ferreira A. Molecular characterization of canine parvovirus variants (CPV2a, CPV-2b, and CPV-2c) based on the VP2 gene in affected domestic dogs in Ecuador. Veterinary World. 2018; 11(4): 480.

[7] Decaro N, Buonavoglia C, Barrs V. Canine parvovirus vaccination and immunisation failures: Are we far from disease eradication? Veterinary Microbiology. 2020; 108-760.

[8] Desario C, Decaro N, Campolo M, Cavalli A, Cirone F, Elia G, Martella V, Lorusso E, Camero M, Buonavoglia C. Canine parvovirus infection: which diagnostic test for virus. Journal of Virological Methods. 2005; 126: 179-185.

[9] Dogonyaro B. Molecular characterization of canine parvovirus strains from Domestic Dogs in South African and Nigeria. MSc thesis. 2010; 1-21.

[10] Dong B, Zhang G, Zhang J, Bai J, Lin W. A systematic literature review and meta-analysis of characterization of canine parvoviruses 2 prevalent in mainland China. Virology Journal. 2020; 17(1): 1-10.

[11] Ernest E. Canine parvovirus: pet health topic in infectious diseases at Michigan Ave Animal Hospital. Pet focus, Animal Clinic Cent. 2009; 1-2.

[12] Ettiger S, Feldman E. Textbook of Veterinary Internal Medicine 4th (Ed). W.B. Saunders Company. 2005; 67956803.

[13] Ettinger S, Feldman E. Textbook of Veterinary Internal Medicine. W.B. Saunders Company. 1995; 6795-6799.

[14] Gombac M, Svara T, Tadic M, Pogacnik M. Retrospective study of canine parvovirus in Slovenia. Case Report. Slovenian Veterinary Research. 2008; 45(2): 73-78. 
[15] González H, Huaracán B, Aguirre I. First report of molecular detection of Carnivore bocaparvovirus 1 (former CnMV: Canine Minute Virus) in Chilean domestic dogs. Australian Veterinary Journal Science. 2020; 52(2): 6365.

[16] Hartmann K, Steutzer B. Feline parvovirus infection and associated diseases. Pubmed. 2014.

[17] Holmes E, Parrish C, Dubovi E, Shearn B, Gerhold R, Brown J, Fox K, Kohler D, Allison A. Requent Cross Species Transmission of Parvoviruses among Diverse Carnivore Hosts. Journal of Virology. 2013; 87(4): $2342-2347$.

[18] Hong C, Decaro N, Desario C. Occurrence of canine parvovirus type 2C in United State. Journal of Veterinary. 2000; 19: 535-539.

[19] Horiuchi M, Yamaguchi Y, Gojobori T, Mochizuki M, Nagasawa H, Toyoda Y, Ishiguro N, Shinagawa M. Differences in the evolutionary pattern of feline panleukopenia virus and canine parvovirus. Virology. 1988; 249(2): 440452 .

[20] Horwitz D. Blackwell's five-minute veterinary consult clinical companion: canine and feline behavior. John Wiley and Sons. 2018.

[21] ICTV. Parvovirus. In: ICTV, The Universal Virus Database, Columbia University, New York, USA. 2006.

[22] Ikeda Y, Mochizuki M, Naito R, Nakamura K, Miyazawa T, Mikami T, Takahashi E. Predominance of canine parvovirus (CPV) in unvaccinated cat populations and emergence of new antigenic types of CPVs in cats. Virology. $2000 ; 278(1): 13-19$.

[23] Kennedy M. Role of Immunization. Clin. Smal. Ani. Int. Med. 2020; 1565-1570.

[24] Khan C, Line S. The merk veterinary manual. 9th (Ed), Merck and Co, New Jersey. 2005.

[25] Kuwabara M, Nariai Y, Horiuchi Y, Nakajima Y, Yamaguchi Y, Horioka I, Kawanabe M, Kubo Y, Yukawa M, Sakai T. Immunological effects of recombinant feline interferon $\omega$ (KT80) administration in the dog. Medical Microbiology and Immunology. 2006; 50(8): 637-641.

[26] Macintire D. Management of Severe Parvoviral Enteritis: Preceed. West. Veterinary Conference. 2004.

[27] Macintire D. Treatment of Severe Parvoviral Enteritis. Proceedings of the CVC Emerald Coast Veterinary Conference, Kansas City. 2008.

[28] Marks S. Rational Approach to Diagnosing and Managing Infectious Causes of Diarrhea in Kittens. August's Consultations in Feline Internal Medicin. 2016; 7: 1-22.

[29] Martin V, Najbar W, Gueguen S, Grousson D, Eun H, Lebreux B, Aubert A. Treatment of canine parvoviral enteritis with interferon omega in a placebo controlled challenge trial. Veterinary Microbiology. 2002; 89(23): $115-127$.

[30] Mazzaferro E. Update on Canine Parvoviral Enteritis. Veterinary Clinics: Small Animal Practice. 2020; 50(6): 1307-1325.

[31] Mosallanejad B, Ghorbanpoor N, Avizeh R. Prevalence of Canine parvovirus (CPV) in diarrheic dogs referred to veterinary hospital in Ahvaz Archives of Razi Institute. 2008; 63(2): 41-46.

[32] Ogbu K, Anene B, Nweze N, Okoro J, Danladi M, Ochai S. Canine Parvovirus: A Review. International Journal of Sciences and Applied Research. 2017; 2(2): 74-95.

[33] Ogbu K, Mira F, Purpari G, Nwosuh C, Loria G, Schirò G, Guercio A. Nearly full length genome characterization of canine parvovirus strains circulating in Nigeria. Transboundary and Emerging Diseases. 2020; 67(2): 635-647.

[34] Oh J, Ha G, Cho Y, Kim M, An D, Hwang K, Lim Y. Park B, Kang B, Song D. One-Step Immunochromatography Assay Kit for Detecting Antibodies to Canine Parvovirus. Clinical and Vaccine Immunology. 2006; 13(4): 520-524.

[35] Savigny M, MacIntire D. Use of oseltamivir in the treatment of canine parvoviral enteritis. Journal of Veterinary Emergency and Critical Care. 2010; 20(1): 132-142.

[36] Schatzberg S, Haley N, Bar S, DeLahunta A, Kornegay J, Sharp N. Polymerase Chain Reaction Amplification Of Parvoviral DNA From The Brains Of Dogs And Cats With Cerebellar Hypoplasia. Cornell University Hospital for Animals, Ithaca, NY, College of Vet Med, University of Missouri, Columbia, MO, Vancouver, British Columbia, Canada. 2002.

[37] Shackelton L, Parrish C, Truyen U, Holmes E. High rate of viral evolution associated with the emergence of carnivore parvovirus. Proceedings of the National Academy of Sciences of the United States of America. 2005; 102(2): 379-384. 
[38] Silverstein D. Intensive Care Treatment of Severe Parvovirus Enteritis. Journal of Veterinary Emergency and Critical Care. 2003.

[39] Steinel A, Munson L, Van V, Truyen U. Genetic characterization of feline parvovirus sequences from various carnivores. Journal General Virology. 2000; 8: 345-350.

[40] Terzungwe T, Thaddaeus A, Saganuwan S, Aondonenge T, Washima A, Samuel N. The epidemiology of canine parvovirus enteritis in dogs of Makurdi, Benue State, Nigeria. Veterinary World. 2018; 8(3): 48-54.

[41] Tijssen P, Arella M. Parvoviridae, Structure and reproduction of densonucleosis viruses. Atlas invertebrate Virus. 2017; 41-53.

[42] Tilley L, Smith F. Canine parvovirus infection. Blackwell's Five Minutes Veterinary Consult: Canine and feline 5th (Ed). 2011; 1-3.

[43] Truyen U. Evolution of canine parvovirus, a need for new vaccines. Veterinary Microbiology. 2006; 117(1): 9-13. 